\section{UMA REVISTA EM MOVIMENTO: CONTRIBUIÇÕES PARA A SUBÁREA SOCIOCULTURAL E PEDAGÓGICA DA EDUCAÇÃO FÍSICA BRASILEIRA (2004-2014)}

\author{
A JOURNAL ON THE MOVE: CONTRIBUTIONS TO THE SOCIO-CULTURAL AND \\ PEDAGOGICAL SUBFIELD OF BRAZILIAN PHYSICAL EDUCATION (2004-2014)
}

\author{
UNA REVISTA EN MOVIMIENTO: CONTRIBUICIONES PARA LA SUBAREA \\ SOCIOCULTURAL Y PEDAGOGICA DE LA EDUCACIÓN FÍSICA BRASILEÑA \\ (2004-2014)
}

\section{Felipe Ferreira Barros Carneiro*, Amarílio Ferreira Neto**, Juliana Martins Cassani Matos ${ }^{\star \star}$, Murilo Eduardo dos Santos Nazário ${ }^{\star \star *}$, Wagner dos Santos*}

Resumo: Demonstra a contribuição da revista Movimento para a subárea sociocultural e pedagógica da Educação Física brasileira entre 2004 e 2014. De natureza quantiqualitativa, faz uso de técnicas da Cienciometria e Bibliometria para analisar os seguintes indicadores: periodicidade; vínculo com a pós-graduação; presença de financiamento; tipo de autoria; formação acadêmica; relação com grupos de pesquisa; e vínculo institucional. Os resultados evidenciam: o crescimento de trabalhos coletivos como tendência no campo científico da área; a atuação da revista Movimento, que veicula pesquisas produzidas no país e internacionalmente; e a necessidade de políticas que potencializem os estudos desenvolvidos na "periferia" do Sistema Nacional de pósgraduação.
Keywords

Periodicals.

Scientific and technical activities.

Graduate education.

Bibliometric

indicators.

Palabras clave Publicaciones periódicas. Actividades científicas y tecnológicas. Educación de posgrado. Indicadores bibliométricos.
Abstract: This paper shows the contribution of journal Movimento to the socio-cultural and pedagogical subfield of Brazilian Physical Education between 2004 and 2014. As a quantitative and qualitative work, it uses Scientometric and Bibliometric techniques to analyze the following indicators: frequency; link with post-graduate studies; funding; type of authorship; academic education; relationship with research groups; and institutional affiliation. The results show increase in collective works as a trend in the PE scientific field; Movimento's performance in publishing studies produced in Brazil and abroad; and the need for policies that strengthen studies developed in the "periphery" of the National System of Post Graduation.

Resumen: Demuestra la contribución de la revista Movimento para la subárea sociocultural y pedagógica de la Educación Física brasileña, entre 2004 y 2014. De naturaleza cuanti-cualitativa, utiliza técnicas de la Cienciometría y Bibliometría para analizar los siguientes indicadores: periodicidad, vínculo con el posgrado, presencia de financiación, tipo de autoría, formación académica, relación con grupos de investigación y vínculo institucional. Los resultados muestran: el crecimiento de trabajos colectivos como tendencia en el campo científico del área, la actuación de la revista Movimento que vehicula investigaciones producidas en el país e internacionalmente y la necesidad de políticas que potencialicen los estudios desarrollados en la "periferia" del Sistema Nacional de Posgrado.
* Instituto Federal de Ciência e Tecnologia do Espírito Santo. Vitória, ES, Brasil. E-mail: felipefbcarneiro@gmail.com

** Universidade Federal do Espírito Santo. Vitória, ES, Brasil.

E-mail: amariliovix@gmail.com

*** Universidade Vila Velha. Vila Velha, ES Brasil. E-mail: murilo.nazario@uvv.br

Recebido em: 21-10-2015 Aprovado em: 11-12-2015 (c) (i) () Licence 


\section{INTRODUÇÃO}

No atual cenário da ciência e tecnologia no Brasil, o Sistema Nacional de Pós-Graduação (SNPG), mesmo com suas mazelas, ${ }^{1}$ tem se configurado como uma política pública de notório desempenho no que se refere à promoção e ao desenvolvimento qualitativo de pesquisa científica e formação de massa crítica. Nas últimas duas décadas, como ponderam Veloso et al. (2003), Doutores (2010) e Nascimento (2010), observamos um crescimento na pós-graduação que fez com que o país ganhasse destaque no cenário da ciência na América Latina. ${ }^{2}$

Constituindo um desafio instigante dentro desse sistema, a comunicação científica atua como uma engrenagem para o desenvolvimento da pós-graduação ao mesmo tempo em que é impulsionada por ele, na medida em que se apresenta como importante meio de transferência e compartilhamento de informação técnico-científica. Nos termos de Meadows (1999), a comunicação é tão vital para a ciência quanto para a própria pesquisa, no caso brasileiro, também para o próprio SNPG.

Na vanguarda dessa estrutura, encontra-se o que Job e Freitas (2010) denominam de canais informais (comunicações orais e congressos) e formais (classicamente estabelecidas por livros e periódicos científicos), que se apresentam como "lugares estratégicos" (CERTEAU, 1994) para a circulação das vozes em consonância e dissonância no campo. Assim, quanto mais renome um veículo de informação tiver, mais valor ele agrega aos artigos veiculados sobre sua chancela, ao passo que esse processo contribui para a valorização do próprio canal de comunicação.

No campo de Educação Física, especialmente em sua área sociocultural e pedagógica, as disputas por espaços de publicação mais qualificados têm se mostrado um importante desafio para os pesquisadores envolvidos com a pós-graduação, principalmente em razão da escassez de periódicos de estratos superiores em língua portuguesa e que recebam produções com características das humanidades. Esse cenário pode ser observado sobretudo na atual conjuntura do campo em que a revista Movimento é o periódico com maior qualificação nacional, classificada como estrato A2 no sistema Webqualis.

Esse desafio apontado por Job (2015) se torna ainda maior em razão da necessidade de sobrevivência dos programas de pós-graduação em Educação Física que, em sua maioria, exigem a submissão/publicação de artigos em periódicos classificados no Webqualis entre A1B5, para obtenção do título de mestre, e A1-B1 para titulação em nível de doutoramento (SILVA; GONÇALVES-SILVA; MOREIRA, 2014).

Para a área sociocultural e pedagógica, a revista Movimento tem desempenhado um papel relevante pois, em seu escopo, abre espaço somente para a veiculação de pesquisas sobre as temáticas em interface com as Ciências Humanas e Sociais, mais especificamente em seus aspectos pedagógicos, históricos, políticos e culturais, o que favorece o desenvolvimento dos programas de pós-graduação e/ou linhas de pesquisa com características das humanidades.

Outra questão pertinente refere-se ao monitoramento da atividade científica, do seu impacto e de seus resultados. Para tanto, foram elaborados métodos de avaliação quantitativos e qualitativos que possibilitam aferir os níveis de desenvolvimento alcançados por uma área

1 Como o produtivismo acadêmico levantado por Sguissardi e Silva Júnior (2009).

2 Paradoxalmente, já apontado por Lovisolo (1997), ao comparar os modelos de formação de comunidades científicas no Brasil e na Argentina. 
de conhecimento, quais sejam: as taxas de produtividade dos pesquisadores, o potencial de crescimento das instituições e cursos e a determinação de escalas de prioridades para a distribuição de recursos.

O campo de pesquisa que se propõe aos estudos dessa natureza é conhecido como "bibliografia estatística" ou bibliometria. Consiste na aplicação de técnicas estatísticas e matemáticas para descrever aspectos da literatura e de outros meios de comunicação (VANTI, 2002). A análise bibliométrica constitui instrumento básico no estudo dos fenômenos da comunicação científica, adquirindo importância ao utilizar um método útil para mensurar a repercussão de determinados autores ou periódicos na comunidade científica. Esse tipo de investigação tem se fortalecido como uma das maneiras de avaliar a produção científica em diferentes áreas do conhecimento (CARDOSO et al., 2005).

O processo de construção e desenvolvimento dos índices ${ }^{3}$ de avaliação da produção acadêmica, sua utilização e consequências ocupam espaço de discussão desde a década de 1950 e vêm se aprimorando com o seu desenvolvimento (CURTI et al., 2001; GARFIELD, 1955, 1999; MEHO, 2007). Desde então, artigos têm sido publicados com o intuito de melhor compreender a avaliação da produção das diferentes áreas do conhecimento e, assim, entender a amplitude e a natureza das atividades de pesquisa desenvolvidas em diversos países e instituições. Em face da problematização apresentada, o objetivo é demonstrar a contribuição da revista Movimento para a subárea sociocultural e pedagógica da Educação Física brasileira entre 2004 e 2014, bem como identificar as características da comunidade científica que veicula suas pesquisas nesse periódico.

\section{METODOLOGIA}

Esta pesquisa tem natureza quanti-qualitativa e se caracteriza pelo uso de técnicas direcionadas à análise cienciométrica e bibliométrica. A cienciometria ${ }^{4}$ abarca 0 estudo das ciências com o objetivo de compreender sua estrutura, evolução e conexões. Para isso, baseiase em indicadores bibliométricos construídos a partir de documentos publicados em canais especializados e que são empregados como medidas indiretas da atividade da pesquisa científica. Esses indicadores contribuem para a compreensão dos objetivos da pesquisa, das estruturas da comunidade científica, do seu impacto social, político e econômico.

$\mathrm{Na}$ análise da produção científica, existe um conjunto expressivo de indicadores bibliométricos. Dentre eles, destacamos: indicadores de produção e indicadores de ligação. Os indicadores de produção científica são construídos pela contagem do número de publicações por tipo de documento (livros, artigos, publicações científicas, relatórios etc.), por instituição, área de conhecimento, país etc. Já os indicadores de ligação são construídos pela coocorrência de autoria, citações e palavras. São aplicados na elaboração de mapas de estruturas de conhecimento e de redes de relacionamento entre pesquisadores, instituições e países (SANTOS; KOBASHI, 2005).

\footnotetext{
3 Como mostra Meho (2007), o índice $h$ ( $h$-index), o índice a (a-index) e o índice $g$ ( $g$-index).

4 Vanti (2002, p. 153) informa que o termo surgiu na antiga URSS e na Europa Ocidental e foi empregado principalmente na Hungria. Originalmente, como ressalta a autora, referia-se à aplicação de métodos quantitativos para o estudo da história da ciência e o progresso tecnológico. Suas primeiras definições a consideravam como "[...] a medição do processo informático, onde o termo 'informático' significava a disciplina do conhecimento que estuda a estrutura e as propriedades da informação científica e as leis do processo de comunicação". O termo alcançou notoriedade em 1977, com o início da publicação da revista Scientometrics, editada inicialmente na Hungria, e passou a despertar o interesse acadêmico na década de 1980, quando o Institut for Scientif Information (ISI) vendeu sua base de dados para diferentes instituições como uma ferramenta auxiliar na elaboração de políticas científicas.
} 
Esses indicadores contribuem para a compreensão da estrutura da comunidade científica, do objetivo particular da pesquisa ou do seu impacto social, político e econômico. Contudo, não representam uma "verdade" sobre o estado da ciência e da tecnologia, mas são aproximações da realidade ou uma expressão incompleta dela (SANTOS; KOBASHI, 2005).

Computados dentro do rigor metodológico devido e interpretados a partir das especificidades e práticas de produção bibliográfica de cada área de conhecimento, os indicadores bibliométricos são úteis e importantes para entendermos o ciclo de gestação, reprodução e disseminação da ciência e também o aprimoramento da política científica e tecnológica nacional (MUGNAINI; JANUZZI; QUONIAM, 2004).

Diante do exposto, o levantamento dos dados foi feito por meio de consulta aos exemplares eletrônicos disponibilizados no site da revista Movimento. Foi criado um banco de dados composto pelos seguintes indicadores bibliométricos: quantidade de artigos veiculados em cada número da revista; tipo de autoria (individual ou coletiva); distribuição de autores por artigo; titulação; vínculo institucional e área de atuação na pós-graduação (quando existente); relação com grupos de pesquisa; e presença de financiamento.

A coleta foi realizada tomando como referência as informações disponibilizadas pelos próprios autores nos textos. Porém, quando os dados não se apresentavam disponíveis nas publicações, ampliaram-se as buscas para as informações presentes nos Currículos Lattes dos pesquisadores que assinaram os artigos, onde foram checadas as informações sobre grupos de pesquisa ${ }^{5}$ e seus vínculos institucionais e/ou orientações em nível de pós-graduação stricto sensu, no momento da publicação do texto. Esse procedimento foi realizado com o objetivo de dar mais confiabilidade aos dados referentes à relação com a área e vínculo com um programa de pós-graduação.

Os dados foram categorizados de modo a apresentar o panorama organizacional da comunidade acadêmica, que ganhou circulação por meio da revista Movimento no período de 2004-2014. As análises e as tabulações foram realizadas por gráficos e tabelas desenvolvidos no Microsoft Excel, de modo que cada categoria apresentada originou uma visualização sistematizada das informações reunidas no instrumento de coleta de dados. Sempre que possível, foi traçada uma linha de tendência com a razão $\mathrm{R}^{2}$ mais próxima de $1 .{ }^{6}$

Esse processo potencializou a análise das fontes, bem como o diálogo com a literatura específica. Esses dados auxiliaram a perceber as diferentes particularidades da área à qual a Educação Física está vinculada - Área 21 - e suas normativas, permitindo identificar os rumos que tem tomado a produção científica veiculada na revista Movimento, assim como a natureza do próprio periódico.

\section{PERIODICIDADE}

A periodicidade de uma revista é um importante indicador de qualidade de um veículo de comunicação científica, uma vez que indica a seriedade e empenho da equipe editorial envolvida no processo de gerenciamento do periódico.

5 As informações sobre os grupos de pesquisa também foram confirmadas no site do diretório de grupos do CNPq. 
Conforme indicado no Gráfico 1, no período de 2004 e 2014, a revista Movimento manteve regularidade na veiculação de seus números, apresentando uma performance condizente com a exigida para a estratificação em que o periódico se enquadrava em determinado triênio, ${ }^{7}$ de acordo com o sistema de avaliação Qualis Capes, que encontra resistência em sua fórmula classificatória em áreas do conhecimento com distintas características. ${ }^{8}$

Gráfico 1 - Periodicidade da revista Movimento em 2004-2014

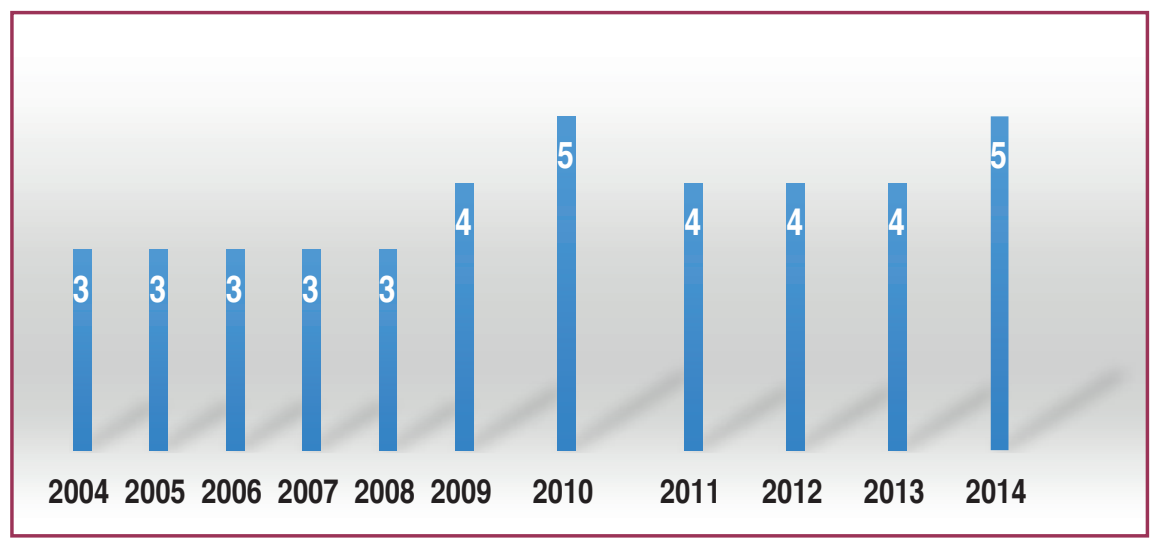

Fonte: Os autores

Entre 2004 e 2008, a Movimento apresentou publicações quadrimestrais, fazendo circular três números por ano, o que era condizente com o Qualis ${ }^{9}$ que a revista apresentava nesse período. No sistema adotado pela Capes, entre 2003 e 2006, a revista foi classificada como "B nacional", o que na época gerou bastante insatisfação por parte do seu corpo editorial. Segundo o Editorial (2005), era inaceitável essa qualificação em razão do desempenho do periódico nos triênios 2001-2003 e 2004-2006, em que a revista apresentava performance equivalente ao nível "C internacional".

Os editores da revista sempre foram claros quanto à busca de uma qualificação do periódico e uma equalização no processo de avaliação e classificação das revistas da subárea sociocultural e pedagógica, em relação aos periódicos que priorizam as pesquisas da subárea de biodinâmica. Nesse período, a insatisfação era tamanha a ponto de, em Editorial (2006), serem questionadas a seriedade e a imparcialidade dos critérios de avaliação e dos avaliadores.

Com a mudança no sistema de avaliação da Capes a partir do triênio 2007-2009, a Movimento passou a compor o estrato B2 ${ }^{10}$ nas revistas científicas da Área 21 , o que the conferia um status de periódico secundário dentro do sistema Qualis, o que sempre gerou incômodo aos editores.

É possível que, em razão desse fato, no primeiro volume de 2007, tenha havido uma importante mudança de comportamento por parte dos editores da revista, que passaram a adotar, mesmo a "contragosto", os "[...] arbítrios dos chamados 'indexadores de prestígio"' (EDITORIAL, 2007), compreendendo a relevância dessa medida para a qualificação da revista e para a sobrevivência dos pesquisadores na pós-graduação.

\footnotetext{
7 Recentemente a periodicidade da avaliação da Capes passou para quadrienal.

8 Como pode ser visto em Pereira (2009), Garcia (2009), Caramelli (2010). Positivas ou negativas, as críticas geradas pelos debates são sempre produtivas, polêmicas e delicadas.

$9 \mathrm{Na}$ época, o sistema de avaliação da Capes adotava seis estratos de classificação para os periódicos científicos, os quais poderiam ser classificados segundo critérios de indexação e organização científica entre os níveis A, B e C de categoria Nacional; e A, B e C de categoria Internacional.

100 sistema passou a ser dividido em classificação regressiva em Qualis A1, A2 e B1 (considerados estratos superiores); B2, B3, B4 e B5; por fim, o estrato $\mathrm{C}$ (revista científica inadequada).
} 
A migração para a plataforma do Sistema Eletrônico de Editoração de Revistas (SEER) permitiu à Movimento alcançar novos patamares de qualidade, melhorando a regularidade e a pontualidade das publicações. Esse posicionamento também possibilitou à revista, no ano de 2009, alterar sua periodicidade para trimestral, passando a publicar quatro números por ano. Essas medidas deram maior confiabilidade ao periódico, o que contribuiu para que a revista recebesse o investimento de indução para o Qualis A2, na Área 21.

Nos anos de 2010-2014, foram publicados dois números especiais: uma edição comemorativa sobre os 70 anos da Escola Superior de Educação Física da Universidade Federal do Rio Grande do Sul (Esef/UFRGS) e a outra relacionada com os 20 anos da revista Movimento. Essas publicações aumentaram a quantidade de fascículos de quatro para cinco números nesses dois anos. A presença dos números especiais também gerou um acréscimo no volume de artigos veiculados pelo periódico no período de 2004-2014, fazendo com que a linha da regularidade de quantidade de artigos oscilasse nos volumes 16 e 20 da Movimento, como observado no Gráfico 2.

Gráfico 2 - Evolução da quantidade de artigos veiculados por fascículos da revista Movimento (2004-2014)

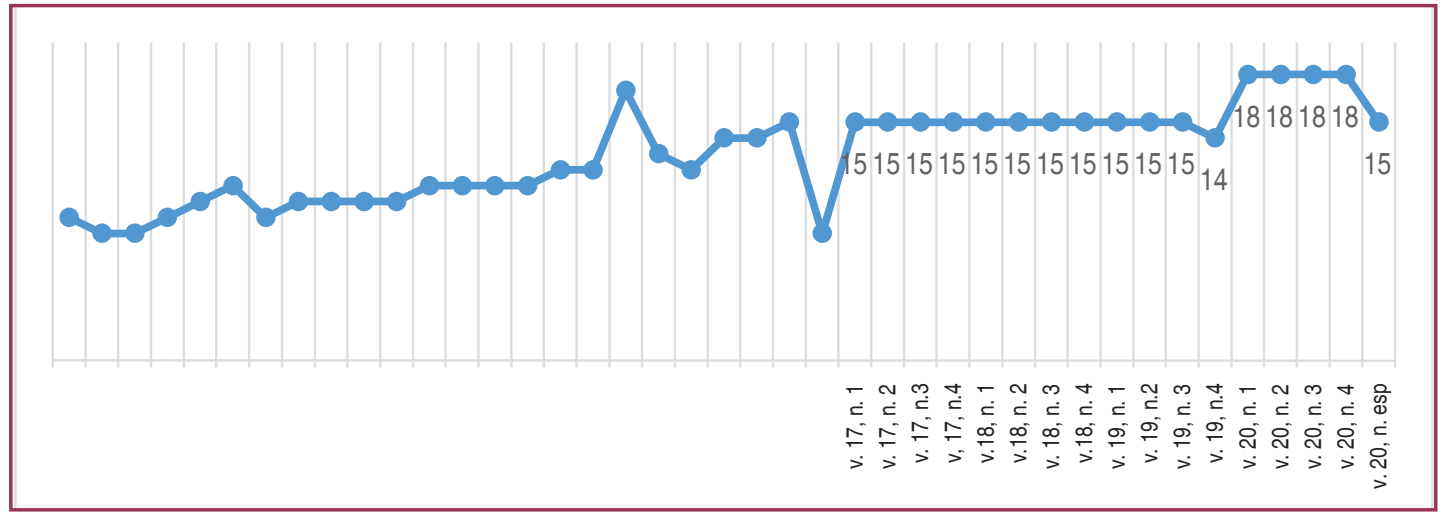

Fonte: Os autores.

O Gráfico 2 demonstra que, nos 38 números da revista Movimento, foram veiculados 531 artigos, com média de 13,97 artigos por fascículo. Esses dados indicam que a revista apresentou uma performance superior à mínima exigida pelo $\mathrm{CNPq}$, para um periódico científico financiado por essa agência, qual seja, cinco artigos por fascículo. ${ }^{11} \mathrm{O}$ crescimento médio de artigos por exemplar da Movimento foi potencializado pelo aumento de pareceristas ad hoc, o que agilizou o processo de avaliação peer review. 0 período também coincidiu com a transformação do periódico em revista digital, o que tem gerado uma economia nos custos de produção no periodismo científico, ${ }^{12}$ facilitando a circulação de um número maior de manuscritos.

\section{PÓS-GRADUAÇÃO}

No Brasil, há uma tendência de que as pesquisas de maior qualidade e impacto sejam provenientes do SNPG, uma vez que os recursos das agências de fomento são, prioritariamente, destinados aos programas de pós-graduação na forma de bolsas, auxílios e financiamentos diversos.

11 Conforme apresentado nas normas para Auxílio Editoração do CNPq, o que pode ser conferido em http://www.cnpq.br/view/-/journal_ content/56_INSTANCE_0oED/10157/25480

12 Ver estudo de King e Tenopir (1998). 
Com base nessa premissa, o Gráfico 3 apresenta a relação das pesquisas veiculadas na revista Movimento com a pós-graduação brasileira no período de 2004-2014. O gráfico mostra uma linha de tendência que indica as oscilações médias dos indicadores analisados, apresentando um panorama da contribuição da pós-graduação para a revista e, consequentemente, do periódico para o SNPG.

As curvaturas formadas pelos picos e vales da linha lançam luz na propensão da ciência na subárea sociocultural e pedagógica da Educação Física, colocando em evidência os movimentos do campo científico que podem ser identificados por meio da análise dos 531 artigos veiculados pela revista Movimento durante o período analisado.

Gráfico 3 - Relação de artigos da revista Movimento com e sem vínculo com a pós-graduação stricto sensu de 2004-2014

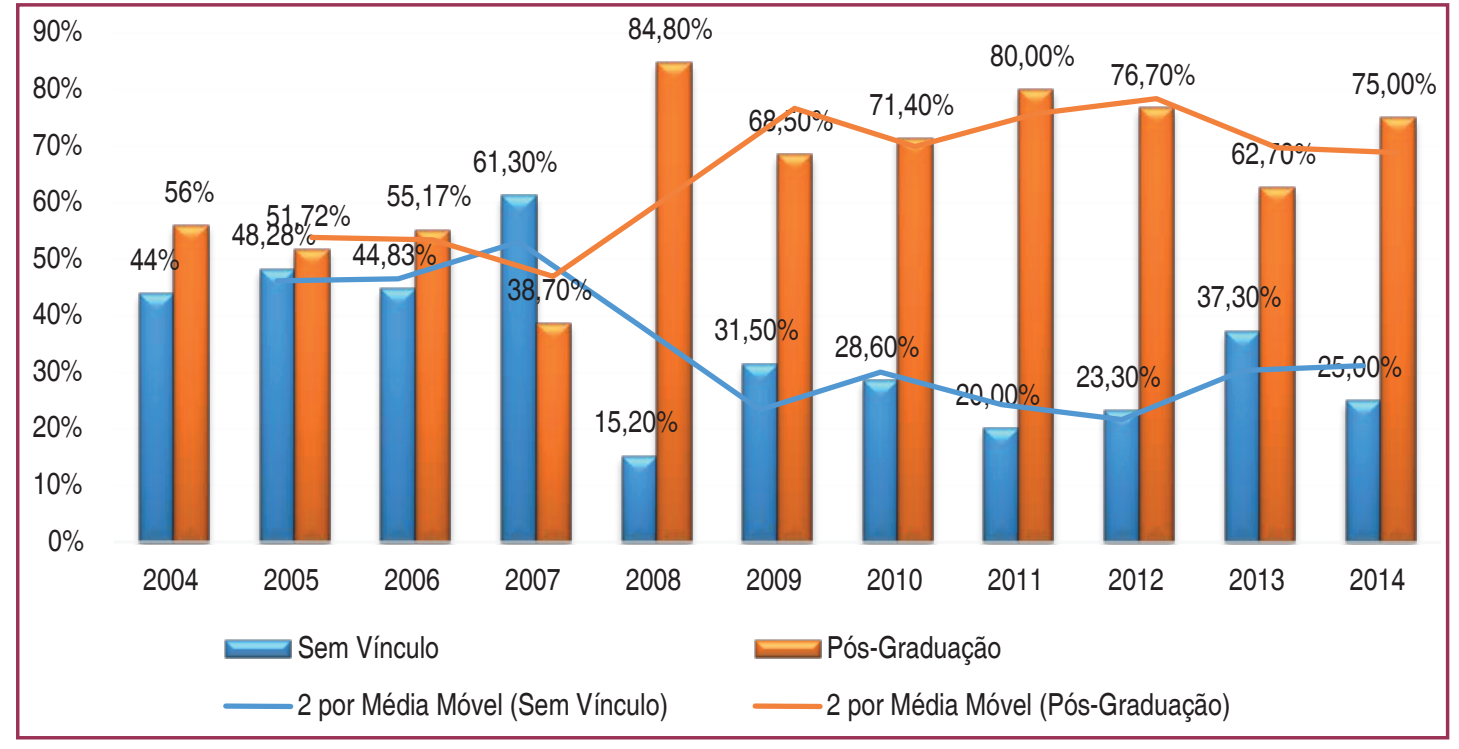

Fonte: os autores

Os dados do Gráfico 3 apresentam dois momentos quanto à relação dos artigos publicados na Movimento com o SNPG. Entre 2004 e 2007, existia uma proximidade entre o percentual de artigos que apresentavam vínculo com programas de pós-graduação e os que não indicavam essa relação. Até o ano de 2007, apresentava-se uma leve tendência de ampliação do quantitativo de textos sem vínculo com o sistema de pós-graduação stricto sensu, apresentando um número superior às produções com relação assumida com programas de mestrado e doutorado.

Assim, se levarmos em consideração que os programas de pós-graduação agregam qualidade à produção científica, podemos levantar três realidades possíveis: a) até 2007 um elevado percentual das pesquisas de maior qualidade estava fora do circuito da pós-graduação; b) a revista não era alvo massivo de escoamento da produção científica da Área 21, portanto não apresentava desempenho relevante para o desenvolvimento da ciência no modelo adotado no Brasil; e c) as críticas proferidas pelos editores à avaliação realizada pela Capes à revista Movimento não encontravam sustentação nesse indicador de qualidade.

Com a submissão da revista aos "modelos arbitrários" relacionados com os indicadores de prestígio dos periódicos, anunciada no Editorial (2007), os dados do Gráfico 3 apontam para uma rápida mudança no indicador de qualidade. A linha de tendência média dos artigos provenientes da pós-graduação eleva-se abruptamente, atingindo pico dessa relação já em 
2008, quando $84,80 \%$ apresentaram vínculo com o SNPG, mantendo uma tendência média sempre acima de $70 \%$ de artigos originários de cursos de mestrado e doutorado.

Os dados indicam que, mesmo sendo questionáveis do ponto de vista político-ideológico, assumir para a revista Movimento os critérios de qualidade de indexadores relevantes foi uma decisão adequada, uma vez que a revista se tornou um importante veículo de comunicação de pesquisa científica da subárea sociocultural e pedagógica presente na Área $21 .^{13}$

Para ilustrar a distribuição das áreas do conhecimento dos artigos veiculados pela Movimento, o Gráfico 4 foi desenvolvido levando em consideração somente os textos com vínculo em programas de pós-graduação. Nesses termos, o gráfico a seguir foi construído com base nos 250 artigos que apresentaram essa condição.

Gráfico 4 - Área de conhecimento dos artigos publicados na revista Movimento 2004-2014

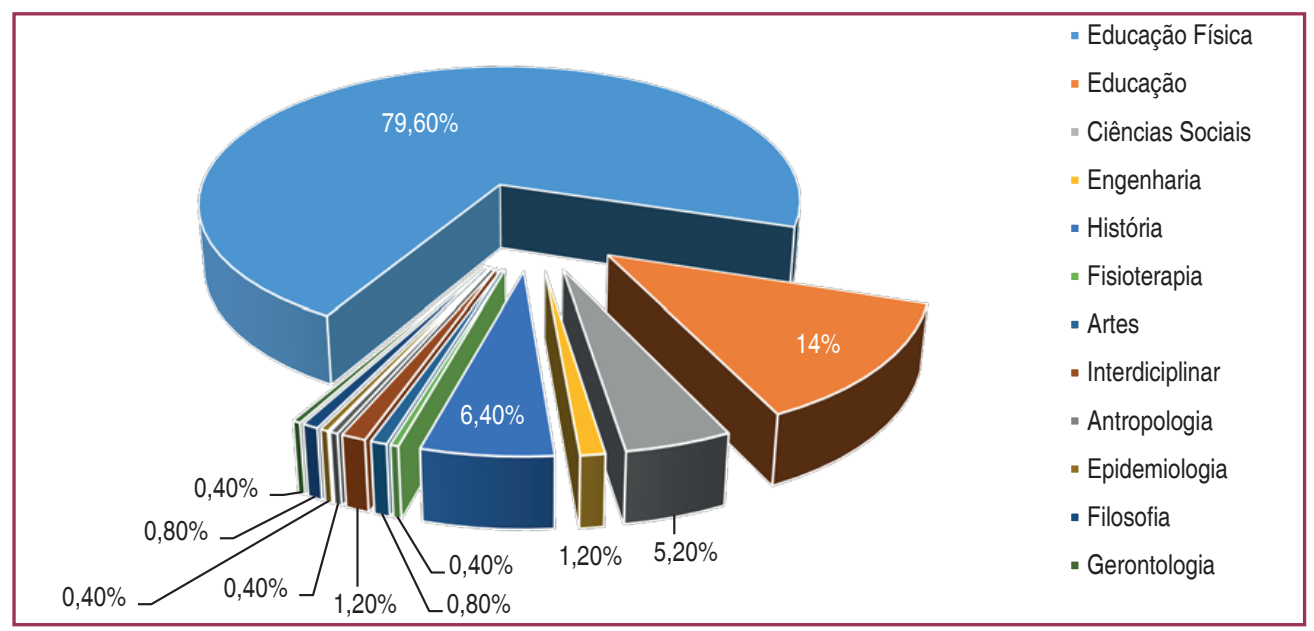

Fonte: os autores

O Gráfico 4 indica que a revista Movimento tem recebido artigos de maneira diversificada, com autores de programas de pós-graduação provenientes de onze campos científicos distintos. É notória a participação dos programas de Educação Física, com 79,60\% das publicações veiculadas. Essa representatividade quantitativa já era de se esperar, em razão da ancoragem da Movimento na Esef/UFRGS, o que denota um caráter estratégico importante desse periódico para a manutenção desses programas.

Pela sua característica sociocultural e pedagógica, é saliente a presença de pesquisas originárias em áreas fronteiriças à Educação Física nos números da Movimento, representadas pelos $20,40 \%$ dos artigos produzidos na pós-graduação, como nas áreas de Educação, Ciências Sociais e História. Conforme demonstrado por Corte (2009) e Carneiro, Ferreira Neto e Santos (2015), esses campos do conhecimento têm contribuído para formar a base epistemológica da área sociocultural e pedagógica da Educação Física, sendo bastante comum a presença de profissionais com essa formação que buscam esses programas para qualificação em nível de mestrado e doutorado. ${ }^{14}$ Assim, é esperado que procurem veicular sua produção em um periódico sedimentado na sua área de origem. ${ }^{15}$

13 Essa característica já fora apontada por Schneider et al. (2009) e contraposta por Stigger et al. (2010). Os dados nos levam a reiterar a posição de que a revista precisa buscar estratégias para se qualificar e, ao mesmo tempo, manter sua identidade.

14 Segundo os dados de Nascimento (2010), até 2003 existiam no Brasil apenas oito programas de pós-graduação stricto sensu em instituições públicas: quatro em universidades federais e quatro em estaduais.

15 Esse movimento torna-se ainda mais relevante para os autores vinculados a programas de pós-graduação em Educação, uma vez que a Movimento também se encontra qualificada como A2 nessa área. Assim, estes aumentam a produtividade no curso e fazem a produção circular na área de Educação Física. 
O Gráfico 4 indica um processo de consolidação da pós-graduação na área, pois, como apontado em mapeamento realizado por Nascimento (2010), até o final da década de 1990, havia poucos programas stricto sensu em Educação Física, sendo comum a busca pela formação em campos científicos afins, principalmente na Educação. Nesses termos, a predominância, na revista Movimento, de pesquisas produzidas por autores vinculados a programas de mestrado e doutorado na área de Educação Física, seja na condição de alunos em formação, seja como professores da pós-graduação, indica uma ampliação do acesso à formação específica na área sociocultural e pedagógica em Educação Física, o que pode representar a captação de mais recursos para o desenvolvimento científico do campo nas agências de fomento.

\section{FINANCIAMENTO DAS PESQUISAS}

A questão da captação de recursos e financiamento de pesquisa é sempre um assunto polêmico em todas as áreas do conhecimento científico. A disparidade na distribuição do fomento é uma das questões mais debatidas na ciência brasileira (YAMAMOTO, 2000), o que faz com que os autores das publicações em periódicos situados nos estratos superiores no Webqualis entrem em incessante disputa pelo aporte financeiro, o que pode possibilitar maior qualificação das práticas científicas.

Como uma das contrapartidas, é comum as agências de apoio exigirem a veiculação de seus nomes nas publicações originadas de pesquisas produzidas com os recursos captados. Desse modo, a presença de pesquisas financiadas nas páginas de um periódico é um forte indicador de qualidade.

O Gráfico 5 apresenta a evolução do quantitativo de pesquisas financiadas que ganharam circulação nos exemplares da revista Movimento entre 2004 e 2014. Os dados demonstram que 9,6\% (51) dos artigos receberam aporte financeiro de agências de fomento, o que pode ser considerado um número muito baixo, quando tomamos como referência a importância desse periódico para a área de Educação Física.

Gráfico 5 - Número de pesquisas financiadas veiculadas na revista Movimento entre 2004 e 2014

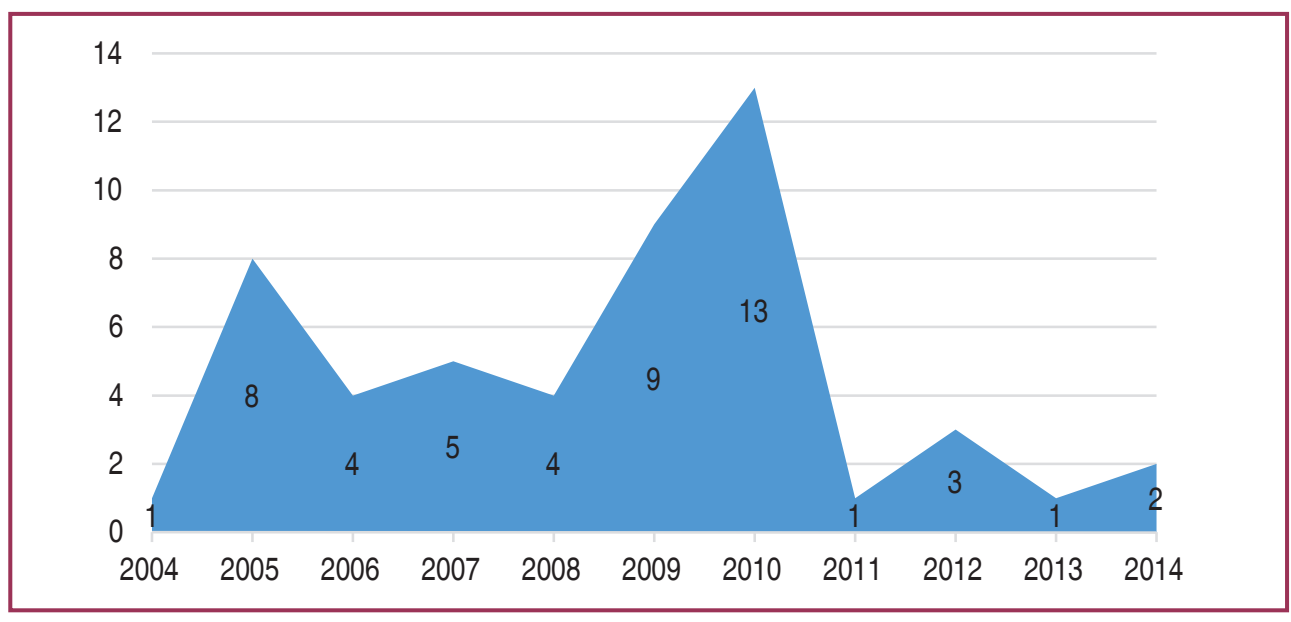

Fonte: os autores

O Gráfico 5 apresenta uma alta irregularidade na quantidade de pesquisas financiadas na revista Movimento, indicando dois picos de elevação e uma queda abrupta. Essa situação 
demonstra que 0 impacto positivo das mudanças de gestão adotadas no periódico a partir de 2007 não encontrou ressonância no volume de pesquisas com aporte financeiro de agências de fomento. Para explicar essa situação, foram levantadas três hipóteses: a) as pesquisas financiadas são encaminhadas para periódicos estrangeiros com maior fator de impacto; b) os recursos destinados ao desenvolvimento de pesquisas na área sociocultural e pedagógica da Educação Física não são suficientemente distribuídos nos programas de pós-graduação; e c) existe um elevado percentual de autores que não informam as agências que subsidiaram as pesquisas.

Para testar as hipóteses foram selecionados, aleatoriamente, dez autores que, no momento das publicações, se encontravam na condição de mestrandos ou doutorandos, em virtude da regularidade de bolsas disponíveis para pesquisadores nesses níveis de formação. Buscamos nos Currículos Lattes desses autores os elementos indiciários para a checagem das hipóteses.

No que diz respeito à publicação em revistas estrangeiras, nenhum dos autores da amostra apresentou em seus currículos artigos veiculados em revistas de fora do país. $\mathrm{Na}$ busca nos currículos, encontrou-se a informação de que nove autores receberam recursos na forma de bolsa de pesquisa para o desenvolvimento de suas teses ou dissertações, indicando o ocultamento da informação das fontes dos recursos financeiros, mesmo com orientação nas diretrizes da revista Movimento de inserir os dados das agências de fomento em seus metadados.

É fato que a questão do financiamento é sempre delicada. Nos tempos atuais, tornase ainda mais complexa com as medidas governamentais de contenção de despesas. Essa política de contenção econômica tem feito os programas de pós-graduação receberem recursos menores em sua principal receita, a verba do Programa de Apoio à Pós-Graduação (Proap) da Capes, o que gerou insatisfação por parte dos coordenadores de área que elaboraram uma carta-manifesto contra o corte de verba.

Porém, provavelmente, o "problema" das pesquisas veiculadas na Movimentonão passa pela questão do financiamento, mas sim pelo "esquecimento" dos pesquisadores de indicar as agências de fomento das quais captaram os aportes financeiros para o desenvolvimento das suas pesquisas.

\section{AUTORIA}

Utilizando como base as 1305 assinaturas autorais, entre estudantes de graduação e pós-doutores que publicaram os 531 artigos veiculados nos números da revista Movimento, nota-se a existência de quatro maneiras de circulação de pesquisas, quais sejam: a publicação de artigos com autoria individual, em duplas, em trios e composições multiautorais (quatro autores ou mais).

O Gráfico 6 demonstra a evolução da composição autoral nos artigos que foram publicados na revista Movimento, no período de 2004-2014, apontando oscilações das formas de fazer veicular a pesquisa da comunidade cientifica. 0 gráfico permite vislumbrar uma tendência a ser seguida no campo científico, no que diz respeito às formas de praticar a ciência na área sociocultural e pedagógica da Educação Física. 
Gráfico 6 - Composição autoral dos artigos veiculados na revista Movimento 2004-2014

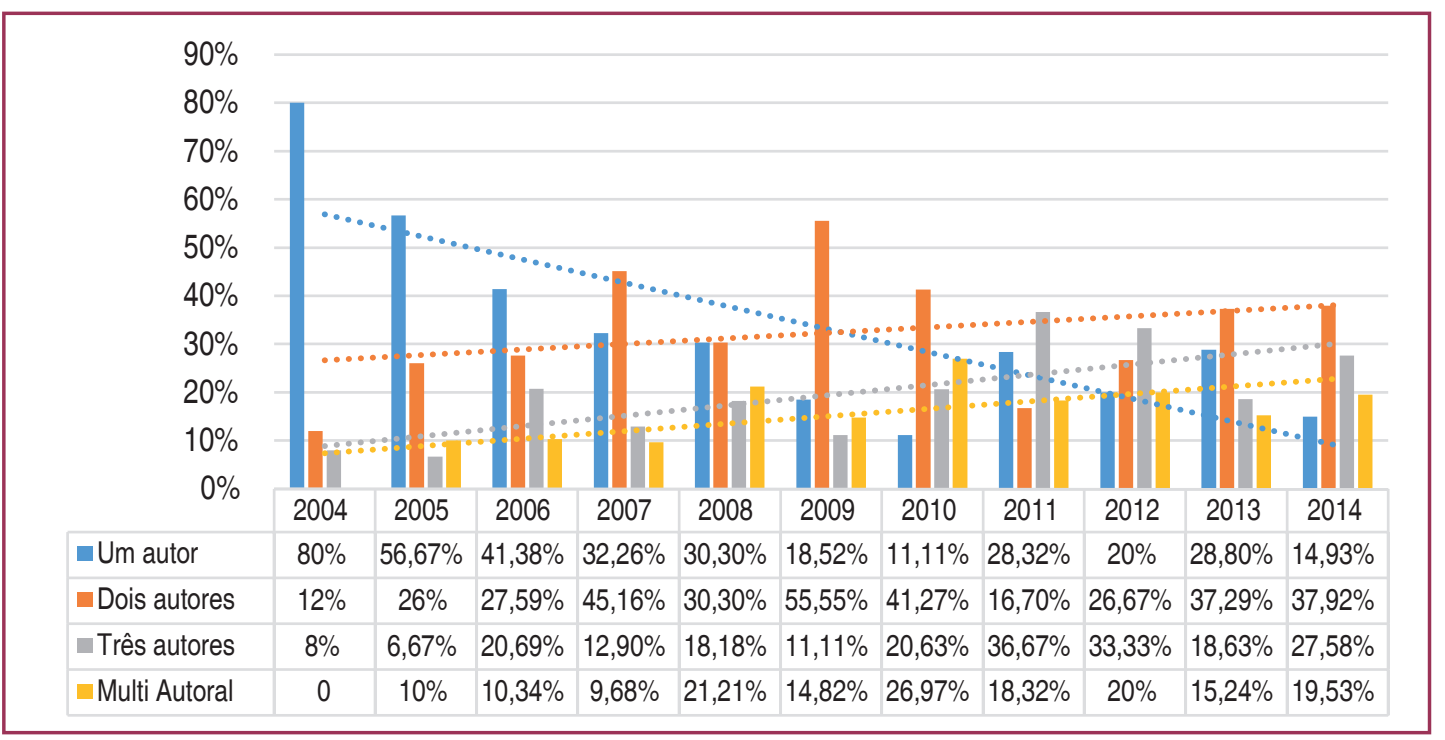

Fonte: os autores.

O Gráfico 6 indica uma mudança de tendência na forma de publicar pesquisas no âmbito da revista Movimento. Gradativamente, é possível observar a alteração do comportamento da comunidade científica, que tem se organizado cada vez mais em autorias coletivas, principalmente em duplas e trios. A publicação da portaria n. 51, de junho de 2004, pela Capes, confere força a essa argumentação, uma vez que esse documento foi elaborado com o objetivo de fixar "[...] normas e procedimentos para a avaliação anual de propostas de cursos de mestrado e doutorado e define a concepção do aplicativo a ser utilizado para 0 encaminhamento de tais propostas" (BRASIL, 2004, p. 1).

Esse documento traz como um dos critérios para a implantação de programas de pós-graduação e de avaliação dos cursos em atividade a existência de um professorado com produção científica qualificada no campo, para assegurar a regularidade do curso. Segundo o mesmo documento, esses processos devem ser fomentados pela organização e maturação de grupos de pesquisa com capacidade para alimentar as áreas de concentração de estudo.

A forma majoritária de composição autoral identificada no periódico ainda pode ser entendida como a forma clássica de publicações nas áreas de humanidades (GOLDIM, 2007), as quais normalmente contam com a figura do orientando, do orientador e de um possível coorientador. Entretanto, o Gráfico 6 aponta uma perspectiva de mudança no modus operandi dessa comunidade acadêmica, indicando que, se mantiver essa tendência, muito em breve a área sociocultural e pedagógica assumirá as mesmas práticas científicas adotadas nas chamadas "ciências duras", no que diz respeito à composição autoral. ${ }^{16}$

Esses caminhos indicados podem ser interessantes para o desenvolvimento do campo, porém devem ser perspectivados com alguma cautela, principalmente com referência às justificativas das participações dos autores dos artigos, para que algumas práticas indesejadas não aconteçam. Sobre o número de pesquisadores assinando um mesmo trabalho, Meadows (1999) pondera que, na comunicação científica, os autores de uma pesquisa deveriam ser mencionados tomando como base a relevância da contribuição de cada pesquisador durante a elaboração do estudo, porém considera que, em artigos nos quais vários autores cooperaram 
em diversos aspectos da pesquisa, a importância relativa de suas colaborações torna-se difícil de determinar.

Desse modo, considerando-se que algumas das produções da revista foram assinadas por dez ou mais autores, ${ }^{17}$ é possível levantar a impossibilidade de se justificar a participação efetiva de todos os pesquisadores. Entretanto, é preciso salientar que essa prática na pesquisa é uma propensão em artigos científicos, pois, com a cobrança cada vez mais acirrada por publicação por parte da Capes, os pesquisadores tendem a utilizar cada vez mais essa prática.

Nesses termos, é possível que algumas práticas indesejadas possam ocorrer (ou terem ocorrido) nos artigos da Movimento, em um cenário que parece se aproximar do que Coimbra Júnior (1998) denomina de "autoria de presente". O termo relaciona-se com os textos em que a autoria é constituída por pesquisadores:

[...] cuja contribuição para a investigação, mesmo bastante periférica, ainda assim se consubstancia na forma de co-autoria, conferindo mérito não inferior àqueles recebidos pelos pesquisadores que efetivamente conceberam, obtiveram financiamentos, executaram e redigiram o trabalho (COIMBRA JÚNIOR, 1998, p. 1).

Segundo Coimbra Júnior (1998), essa prática tem forte relação de reciprocidade, de modo que uma autoria dada como presente se torna uma moeda de troca para uma retribuição futura. Essa rede de "favores" pode produzir carreiras científicas com produtividade bastante elevada, mesmo que não sedimentada na efetiva elaboração de pesquisas originais.

Outras possibilidades de explicação para o ocorrido ressoam na pesquisa de Monteiro et al. (2004). Ao estudarem a questão da autoria na área médica, ponderam sobre alguns desvios e práticas não éticos que frequentemente ocorrem no estabelecimento de autoria em publicações científicas. Essas práticas são identificadas como: autoria convidada, em que 0 nome de um autor é incluso por diversos motivos, seja em razão do seu prestígio, seja para servir de "moeda de troca" no futuro; autoria pressionada, na qual o responsável de um grupo exige a inclusão de seu nome em todos os trabalhos da equipe, mesmo sem sequer tê-los lido.

Nas pesquisas científicas, essas práticas têm implicações importantes, por exemplo, na concessão de financiamento e de promoções acadêmicas. Além disso, ferem "[...] um dos princípios básicos da ciência, que é a transparência, colocando em jogo toda a credibilidade da pesquisa" (MONTEIRO et al., 2004, p. 4). Sem dúvida, esse assunto é polêmico, de modo que esse efeito colaborativo é interpretado como uma espécie de solidariedade corporativa de manutenção e crescimento de grupos de pesquisa e de programas de pós-graduação. Infere-se que esse processo tem objetivos anunciados e necessários à possível ampliação e qualificação da formação profissional em Educação Física. Entende-se, assim, ser importante a constituição de artigos multiautorais, principalmente quando associados a grupos de pesquisa e articulados com projetos de formação de pesquisadores nos diversos níveis da cadeia produtiva da ciência.

Para testar as estruturas das composições autorais, foi calculado o Índice de Colaboração das redes de sociabilidade formadas pelos autores que publicaram na Movimento. Segundo Spinak (1996), esse índice pode ser calculado mediante a somatória do produto da quantidade de autores por artigo (i) com a quantidade de artigos com i autores (Ni) divididos pelo número total de artigos $(\mathrm{N})$, conforme ilustrado na fórmula a seguir: 


$$
\begin{gathered}
\text { Índice de Colaboração (IC) } \\
\qquad \mathrm{IC}=\sum \mathrm{i} . \mathrm{Ni} / \mathrm{N}
\end{gathered}
$$

Onde: $\mathrm{N}=$ total de artigos

$\mathrm{i}=$ quantidade de autores no artigo

$\mathrm{Ni}=$ quantidade de artigos com $\mathrm{i}$ autores

IC = Média ponderada de autores por artigo

Tabela 1 - Proporção da composição autoral pela quantidade de artigos publicados na revista Movimento 2004-2014

\begin{tabular}{ccc}
\hline $\begin{array}{c}\text { Tipo de autoria } \\
\text { (i) }\end{array}$ & $\begin{array}{c}\text { Quantidade de artigos por tipo de autoria } \\
(\mathrm{Ni})\end{array}$ & (i).(Ni) \\
\hline 1 & 145 & 145 \\
2 & 180 & 360 \\
3 & 116 & 348 \\
4 & 43 & 172 \\
5 & 30 & 150 \\
6 & 7 & 42 \\
7 & 2 & 14 \\
8 & 2 & 16 \\
9 & 3 & 27 \\
10 & 2 & 20 \\
11 & 1 & 11 \\
TOTAL (N) & 531 & \\
\hline
\end{tabular}

Fonte: os autores.

A Tabela 1 apresenta a relação do número de artigos publicados na revista Movimento com o tipo de composição autoral dessas produções. Com base nesses dados, obteve-se a seguinte equação:

$$
\begin{aligned}
& I C=1 \cdot 145+2 \cdot 180+3 \cdot 116+4 \cdot 43+5 \cdot 30+6 \cdot 7+7 \cdot 2+8 \cdot 2+9 \cdot 3+10 \cdot 2+11 \cdot 1 / 531 \\
& I C=2,46
\end{aligned}
$$

O índice de colaboração entre os autores que publicaram na revista Movimento aponta para uma elaboração conjunta de 2,46. Isso significa que cada autor se articula, em média, com mais de dois pesquisadores diferentes para fazer circular sua produção.

Segundo Lara e Lima (2009), alguns motivos levam à busca pelo aumento da colaboração, quais sejam: alteração nos padrões e níveis de financiamento; anseio por parte dos pesquisadores em aumentar a popularidade, visibilidade e reconhecimento científico; demanda gradual pela racionalização do poder científico; necessidade de instrumentos em maior escala e complexidade; especialização científica gradativa; avanço das disciplinas nas quais o pesquisador necessita de conhecimentos de outros pesquisadores; profissionalização crescente da ciência; necessidade de adquirir experiência e treinar novos pesquisadores; desejo de trabalhar interdisciplinarmente; necessidade de trabalhar em estreita proximidade física com outros pesquisadores.

A "[...] negociação e a troca na colaboração científica exigem, também, investimentos de ordem sócio-emocional para manter relacionamentos colaborativos [...]" (LARA; LIMA, 2009, 
p. 218), conforme pode ser visto em Carneiro, Ferreira Neto e Santos (2015), ao ponderarem sobre 0 uso de congressos científicos para a formação das networks acadêmicas e acúmulo de capital simbólico. Porém, quando observamos o universo de assinaturas autorais, é possível inferir que o grau de colaboração ainda não atingiu sua potencialidade pois, conforme os dados do Gráfico 6, deve se aprimorar no decorrer dos próximos anos, tendo em vista a tendência de se estabelecer no campo uma produção amplamente colaborativa.

Independentemente das razões que levem os autores a expandir seus índices de produções conjuntas, esse fenômeno deve ser observado de perto pelos editores da revista Movimento e de outros periódicos com a finalidade de traçar as medidas necessárias para se manter a integridade das produções que veiculam, bem como os valores éticos desejados para as práticas de pesquisa no campo científico da área sociocultural e pedagógica da Educação Física.

\section{FORMAÇÃO ACADÊMICA}

Sobre a formação acadêmica dos autores que publicaram na revista Movimento no período de 2004-2014, os dados apontaram para um elevado nível de formação em pósgraduação stricto sensu.

O Gráfico 7 indica um crescimento exponencial na quantidade de doutores assinando os artigos veiculados na revista Movimento, no que diz respeito aos números absolutos de assinaturas autorais, acompanhado de uma participação quase irrelevante de programas lato sensu e de graduados/graduandos. Esse cenário pode ser explicado por dois fatores interligados.

0 primeiro relaciona-se com 0 crescimento da quantidade de artigos publicados por número do periódico. Assim, é de se esperar que os pesquisadores mais qualificados consigam publicar mais artigos. $O$ segundo fator refere-se à melhoria da avaliação da revista no Webqualis, o que a tornou a revista científica brasileira, na área de Educação Física, com melhor posicionamento no ranking da Capes, transformando-a em um lugar estratégico de publicação para os doutores com vínculo na pós-graduação.

Gráfico 7 - Titulação dos pesquisadores que publicaram na revista Movimento 2004-2014

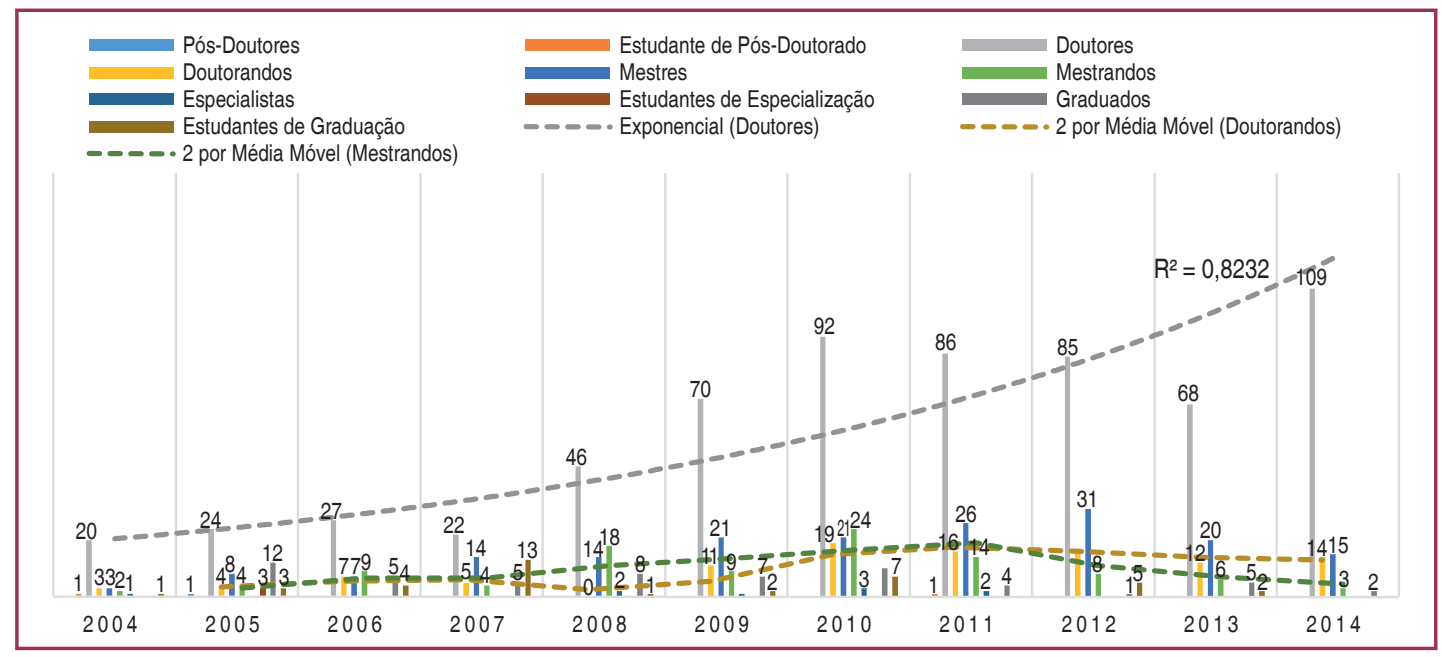

Fonte: os autores. 
Esses dados encontram eco na publicação realizada pelo Centro de Gestão e Estudos Estratégicos (CGEE), que desenvolveu um estudo demográfico sobre o desenvolvimento e distribuição da base técnico-científica brasileira e mostra um crescimento do número de profissionais com formação em nível de mestrado e doutorado.

\begin{abstract}
Há que assinalar também o fato de que o número de programas de doutorado já é relativamente muito menos concentrado geograficamente do que o número de titulados nestes programas. [...]. Ademais, o crescimento mais acelerado no número de programas de doutorado das regiões de menor tradição na pósgraduação pode estar antecipando uma tendência de aceleração da formação de doutores nessas regiões na medida em que os programas mais novos vierem a se consolidar (DOUTORES, 2010, p. 34-35).
\end{abstract}

Esse panorama indica que, na área de Educação Física, assim como ocorre no setor de ciência e tecnologia do país, de maneira geral, os investimentos em políticas científicas, iniciados mais fortemente no Brasil entre as décadas de 1960 e 1970, vêm surtindo o efeito esperado, uma vez que a base técnico-científica nacional tem se consolidado com o gabarito necessário para sustentar a pesquisa científica de ponta.

A presença de uma massa crítica formada por uma ampla malha de doutores é um importante indicador de qualidade para a revista Movimento e salienta o desenvolvimento crescente de recursos humanos do campo científico de Educação Física. Porém, levando em consideração o crescimento da participação da pós-graduação nas publicações da revista, é de causar estranhamento 0 baixo número de estudantes de mestrado e doutorado assinando esses textos (menos de 50\%), principalmente se considerarmos o peso da revista na avaliação da Capes.

Esse panorama pode ser explicado pelas seguintes possibilidades: a) os doutores vinculados a programas de pós-graduação têm publicado sem a presença de estudantes nos periódicos mais qualificados, o que seria um cenário pouco desejado pela Capes, visto que um dos critérios de avaliação dos programas é a publicação conjunta entre docentes e discentes; b) corolário da primeira explicação, os estudantes de mestrado e doutorado estariam publicando em periódicos menos qualificados; e c) em uma visão positiva, as teses e dissertações circulam nos periódicos mais qualificados somente após as respectivas defesas.

A título de ilustração, checaram-se de maneira aleatória as publicações de dez mestres e dez doutores recém-formados. ${ }^{18}$ Os dados indicaram que $80 \%$ dos artigos originários de mestres tinham um vínculo com as pesquisas defendidas durante a formação desses pesquisadores, enquanto $50 \%$ das publicações desses doutores são recortes ou sínteses das suas teses de doutoramento.

A hipótese "c" ganha força no que diz respeito às publicações dos mestres, haja vista o elevado percentual de artigos que são produtos dessas dissertações. Essa característica pode ser salientada em razão do tempo destinado para a elaboração do trabalho de mestrado.

Os dados estimados para os doutores recém-formados denotam um equilíbrio percentual quanto à relação com as teses de doutoramento desses pesquisadores, o que pode significar a relação desses autores com grupos de pesquisa e, consequentemente, a participação em outros projetos de formação desenvolvidos por outros sujeitos em diferentes estágios da cadeia produtiva da ciência.

18 Foram considerados os trabalhos de autores que haviam defendido em até três anos da publicação dos artigos, pois é o período em que a Capes pontua os pesquisadores no que diz respeito ao vínculo institucional. 


\section{GRUPOS DE PESQUISA}

Os dados da revista Movimento indicam que 410 grupos de pesquisa diferentes contribuíram para as publicações veiculadas nesse periódico no período analisado. A identificação dos grupos foi produzida com base nas informações presentes nos artigos, nos Currículos Lattes dos autores e no site do diretório de grupos do CNPq.

O Gráfico 8 demonstra que, no período compreendido entre 2004 e 2014, dos artigos veiculados na revista Movimento, 72,5\% (385) foram assinados por pesquisadores com vinculação acadêmica a grupos de pesquisa. Essa análise preliminar já aponta para uma produção colaborativa entre esses pesquisadores de diferentes grupos, pois foram identificados mais grupos de pesquisa do que o quantitativo de textos produzidos e publicados por eles.

Gráfico 8 - Evolução do quantitativo de artigos na revista Movimento vinculados a grupos de pesquisa no período 2004-2014

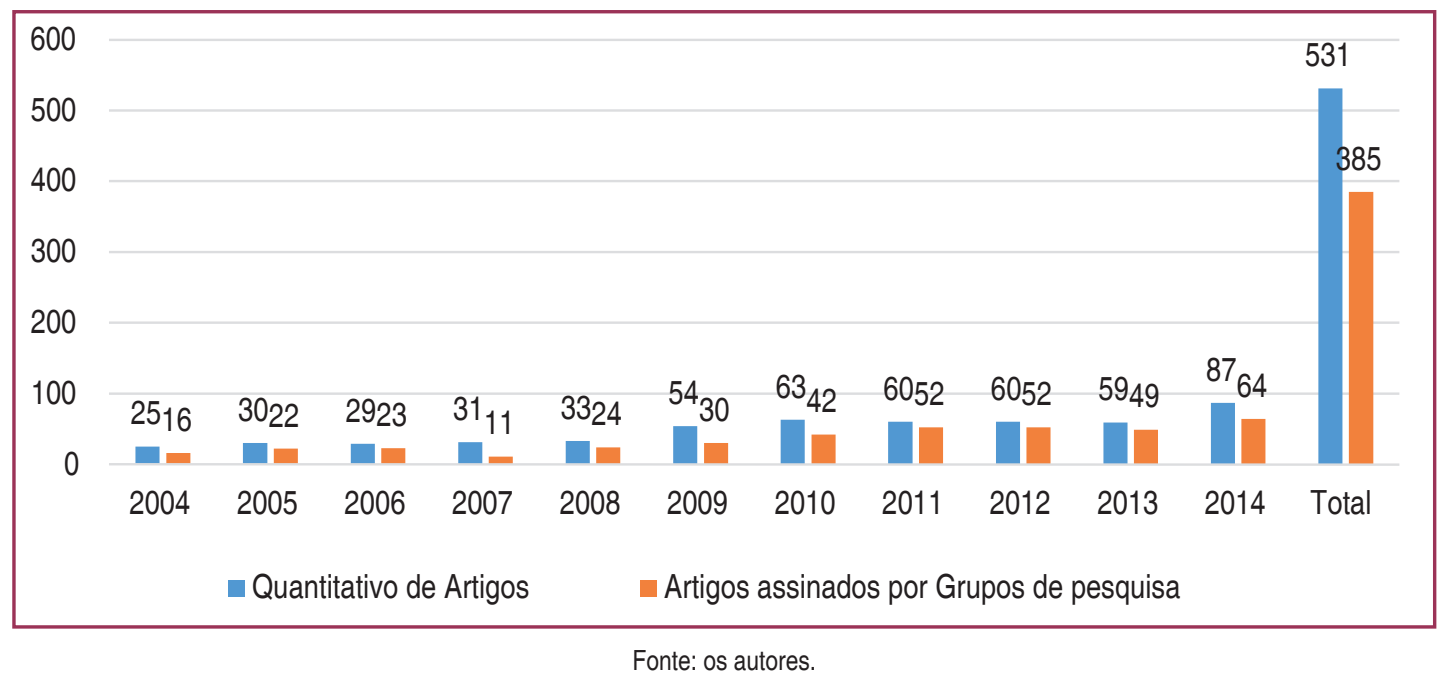

Os dados indicam um crescimento do número de artigos associados a grupos de pesquisa. É possível inferir que esse aumento é um efeito das intervenções da Capes, pois, como nos diz Lovisolo (2003), as políticas públicas brasileiras têm associado a pós-graduação stricto sensu diretamente à pesquisa, abrangendo linhas e terminologias desenvolvidas pela agência, o que, segundo Mocelin (2009), causou uma expansão do número de grupos de pesquisa no Brasil, principalmente a partir dos anos 2000.

A Capes também determina que o desenvolvimento de grupos de pesquisa deve anteceder a criação de programas de pós-graduação. Por razões dessa imposição, segundo Lovisolo (2003), tem aumentado cada vez mais o sentimento de que não estar inserido nesses grupos e não figurar no currículo na Plataforma Lattes constituem um processo de marginalização acadêmica. Para Mocelin (2009), a não vinculação, justificada por Lovisolo (2003), implica limitações das possibilidades de captar recursos nas agências de fomento. Esse movimento tem contribuído substancialmente para o aumento do quantitativo de grupos de pesquisa no campo de Educação Física.

Com base nessa premissa, foi realizado um levantamento dos grupos de pesquisa que tiveram maior circulação de artigos na revista Movimento no período de 2004-2014. Para elaborar essa tabulação, foram selecionados os grupos que publicaram, no mínimo, a média 
de um artigo por volume. Como apresentado no Tabela 2, a partir desse filtro, sete grupos contemplaram os critérios definidos. ${ }^{19}$

Tabela 2 - Grupos de Pesquisa com maior produtividade na revista Movimento 2004-2014

\begin{tabular}{|c|c|c|c|c|c|c|c|c|c|c|c|c|}
\hline GRUPOS & ষ্ণ & 유 & రి & & ర్రి & 오 & 을 & $\overline{\check{N}}$ & $\frac{\sim}{2}$ & $\frac{m}{2}$ & 官 & 覀 \\
\hline Cepels - UFPR & - & 1 & 1 & - & 2 & 1 & 4 & 10 & 1 & 4 & 7 & 31 \\
\hline $\begin{array}{l}\text { Núcleo de Estudos e Pesquisas Educação e } \\
\text { Sociedade Contemporânea - UFSC }\end{array}$ & - & - & 1 & 1 & 2 & 1 & 4 & 3 & 3 & 2 & 3 & 20 \\
\hline Proteoria - Ufes & 1 & 1 & - & - & 1 & 3 & 2 & 4 & 3 & 2 & 3 & 20 \\
\hline Lesef - Ufes & 1 & - & 2 & 1 & 1 & 1 & 3 & 2 & 2 & 2 & 1 & 16 \\
\hline Labec - UFRJ & - & - & - & - & - & - & 1 & 1 & 3 & 2 & 7 & 14 \\
\hline $\begin{array}{l}\text { Laboratório de História do Esporte e do } \\
\text { Lazer SPORT - UFRJ }\end{array}$ & - & - & - & - & - & 1 & & 4 & 1 & 2 & 5 & 13 \\
\hline Gepefic - Unicamp & - & - & - & 1 & - & - & 2 & 3 & 2 & 1 & 2 & 11 \\
\hline
\end{tabular}

Fonte: os autores.

Ao consultar o diretório de grupos do CNPq, fica evidente que os coletivos intelectuais institucionalizados que mais publicaram na revista Movimento (Tabela 2), eram aqueles que tinham seus quadros de recursos humanos organizados com uma quantidade importante de pesquisadores com autoridade e experiência acumulada em pesquisas de cunho sociocultural e pedagógico, perfil de estudos contemplados pelo periódico.

Somados, os artigos desses grupos representam 23,5\% (125) das produções que ganharam circulação na revista nos dez anos analisados. Esse dado indica a formação de uma massa crítica especializada nas discussões fundamentadas nas Ciências Humanas e Sociais e nos debates pedagógicos. Esses grupos de pesquisadores encontram-se vinculados a programas de pós-graduação, portanto as pesquisas por eles desenvolvidas atrelam-se a projetos de formação, o que gera uma demanda qualificada de produções, tencionando a circulação desses artigos no periodismo científico de maior impacto..$^{20}$

É notório que a performance desses grupos oferece uma importante contribuição para o processo de qualificação da Movimento e das pesquisas da subárea sociocultural e pedagógica. Porém, a permanência/ampliação desse cenário pode gerar um "engessamento" epistemológico nessa produção científica, na medida em que circularia uma quantidade relevante de pesquisas alicerçadas em matrizes teóricas e metodologias peculiares a esses grupos de pesquisadores, o que pode se configurar naquilo que Bachelard (1996) denominou de obstáculos epistemológicos.

Assim, é fundamental que outros grupos busquem a expansão de seus quadros de pesquisadores e suas redes de colaboração, de modo a qualificarem sua produção e ampliar sua produtividade. Essas ações aumentariam sua "competitividade científica" (MOCELIN,

19 Os grupos que não contemplaram o filtro estabelecido apresentaram as seguintes performances de publicação: nove artigos (um grupo); oito artigos (quatro grupos); sete artigos (sete grupos); seis artigos (12 grupos); cinco artigos (12 grupos); quatro artigos (15 grupos); três artigos (37 grupos); dois artigos (64 grupos); um artigo (250 grupos).

200 papel dos grupos de pesquisa e suas contribuições efetivas para o desenvolvimento científico ainda é um fenômeno pouco estudado no periodismo científico brasileiro, carecendo de um debate mais qualificado e demandando pesquisas específicas sobre o tema. 
2009), permitindo avanços nas pesquisas de cunho sociocultural e pedagógico, na medida em que os movimentos do campo seriam potencializados pela circulação qualificada de práticas científicas distintas e/ou mesmo concorrentes. Ao mesmo tempo, é importante valorizar e compreender a experiência acumulada pelos grupos que têm contribuído fortemente para a formação de pessoal qualificado e, consequentemente, para o desenvolvimento científico do campo.

Outro ponto relevante sobre o comportamento dessa comunidade acadêmica pode ser visualizado no Gráfico 9, no qual são demonstrados os índices de circulação de grupos de pesquisa na revista Movimento. Uma situação bastante peculiar passa a ser evidenciada, pois observa-se um crescimento bastante intensificado na participação conjunta desses coletivos de pesquisadores na elaboração de um mesmo artigo nesse periódico.

Gráfico 9 - Circulação de grupos de pesquisa nos artigos da revista Movimento de 2004-2014

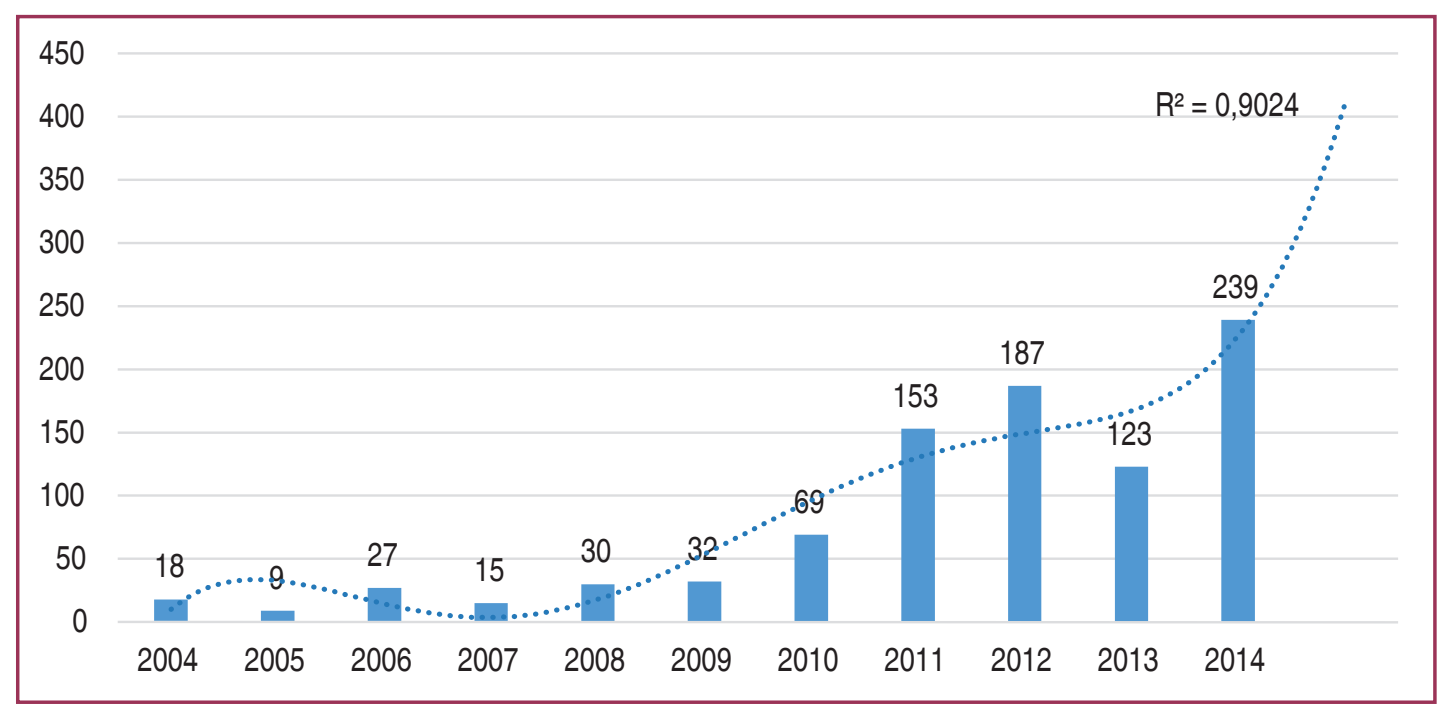

Fonte: os autores.

Os dados do Gráfico 9 apontam um crescimento substancial da autoria associada a mais de um grupo de pesquisa nas produções veiculadas na revista Movimento, principalmente a partir de 2010. A associação de múltiplos grupos nos artigos do periódico se apresentou de três maneiras: a primeira ocorre por meio da autoria colaborativa entre autores ou coletivo de autores com vinculação a grupos de pesquisa distintos; a segunda forma acontece pela relação de um autor com mais de um grupo, na condição de pesquisador ou de liderança, ampliando sua rede colaborativa; a terceira reúne essas duas condições, ou seja, pesquisadores distintos que, por afinidades temáticas, estabeleceram vínculos acadêmicos com mais de um grupo de pesquisa.

Conforme ponderado por Mocelin (2009), o crescimento desses casos pode ser interpretado como uma maneira de melhorar a performance produtiva mediante o aumento da competitividade científica, possibilitando um desempenho mais qualificado na participação da distribuição de recursos financeiros e/ou simbólicos, o que pode contribuir para a consolidação do trabalho coletivo na subárea sociocultural e pedagógica. Porém, tendo como referência o índice de colaboração apresentado por essa comunidade científica, torna-se sustentável a afirmação de que a prática da pesquisa coletiva ainda tem muito a desenvolver nesse campo. 
Desse modo, é possível que o crescimento da circulação desses grupos de pesquisa nos artigos da revista Movimento ainda não seja um processo consolidado de uma cultura científica no campo de Educação Física. Esse comportamento talvez esteja fortemente associado à necessidade de sobrevivência acadêmica diante da realidade das políticas científicas brasileiras, fazendo com que os pesquisadores atuem bastante próximos dos limites da "mediocridade possível", ${ }^{21}$ ou, de fato, consolidem práticas de colaboração científica na subárea sociocultural e pedagógica não vivenciada até o momento.

É prudente que esse movimento seja acompanhado com a cautela necessária para evitar os efeitos negativos de uma fabricação artificial da produtividade acadêmica. Porém, é inegável que desse cenário emerjam possibilidades interessantes, uma vez que a tendência do crescimento das produções científicas multiautorais (Gráfico 6) pode aprimorar o trabalho colaborativo entre os grupos de pesquisa, complexificando as relações científicas e potencializando uma efetiva produção do conhecimento em rede na subárea sociocultural e pedagógica de Educação Física.

\section{VÍNCULO INSTITUCIONAL}

Focalizados os vínculos institucionais dos artigos da revista Movimento no período de 2004-2014, identificou-se a circulação de 257 instituições entre Instituições de Ensino Superior (IES) públicas e privadas, secretarias de ensino estaduais e municipais, institutos federais e outras instituições privadas. ${ }^{22}$

Desse quantitativo, $72 \%$ (185) são nacionais e $28 \%$ (72) internacionais, tendo a revista publicado artigos de instituições situadas nas Américas Latina e do Norte, na Europa e na Oceania. Tomando como referência a extensão do território nacional, bem como o quantitativo de IES no Brasil, é possível afirmar que o projeto editorial da revista Movimento tem sido bemsucedido no que diz respeito ao processo de internacionalização.

Foi realizado um levantamento das instituições que mais veicularam pesquisas ${ }^{23}$ na revista Movimento durante o período em análise. Com base nos critérios estabelecidos, a Tabela 3 apresenta 17 instituições que mais publicaram no periódico, aparecendo em 429 artigos (80,79\% do total de artigos), o que indica as parcerias interinstitucionais. É saliente 0 fato de que o maior quantitativo de publicações é originário de universidades públicas ${ }^{24}$ onde existe a presença de programas de pós-graduação com linhas socioculturais e pedagógicas consolidadas. É perceptível, também, uma elevada presença numérica de instituições localizadas nas regiões Sul e Sudeste do país, configurando uma situação de endogenia necessária ${ }^{25}$ à área de Educação Física. Entretanto, é preciso compreender que é importante para o campo o volume de pesquisa advindo dessas regiões.

Tendo em vista a distribuição econômica do Brasil, é de se esperar que a pesquisa científica mais qualificada seja originada nos polos científicos incrementados pelas políticas de pós-graduação.

\footnotetext{
21 Ver Lovisolo (2003).

22 Clubes, escolinhas e academias.

23 Utilizaram-se os mesmos procedimentos adotados para a organização dos grupos de pesquisa, sendo consideradas as instituições que acumularam dez publicações entre 2004-2014

24 A única exceção nas instituições de maior performance na revista é a extinta Universidade Gama Filho.

25 Entendida como prática que favorece a ampliação quantitativa e qualitativa da área.
} 
Ressalta-se, ainda, que a concentração geográfica dos programas existentes nas regiões Sul e Sudeste fez, e continua fazendo, com que em muitos casos a escolha de um programa de outra área não ocorresse por opção mas por necessidade, às vezes como única alternativa de qualificação (SILVA, 2005, p. 63).

Essa situação também explica a baixa circulação de artigos elaborados por pesquisadores das outras regiões, uma vez que expressa a dificuldade de geração de recursos e estruturas que possibilitem o desenvolvimento da pós-graduação em nível de mestrado e doutorado fora dos grandes centros políticos e econômicos do Brasil. Como observamos na Tabela 3, a UFG aparece como a única universidade que não está localizada nas regiões Sul e Sudeste, com dez artigos publicados.

Tabela 3 - Instituições que mais veicularam artigos na revista Movimento de 2004-2014

\begin{tabular}{|c|c|c|c|c|c|c|c|c|c|c|c|c|}
\hline Instituição & ষ্ণ & ஜి & ஜ্ণ & 옹 & ᄋ్ & ஓ્ઠ & 울 & $\overline{\check{N}}$ & $\stackrel{N}{\check{N}}$ & $\frac{m}{\check{N}}$ & $\stackrel{\nabla}{\circ}$ & $\begin{array}{l}\text { 푬 } \\
\text { 苛 }\end{array}$ \\
\hline UFRGS & 1 & 8 & 5 & 6 & 3 & 10 & 13 & 2 & 7 & 3 & 7 & 65 \\
\hline Ufes & 4 & 2 & 3 & 1 & 3 & 4 & 5 & 9 & 7 & 7 & 4 & 49 \\
\hline Unicamp & 1 & 2 & 1 & 4 & 2 & 6 & 4 & 5 & 8 & 7 & 5 & 45 \\
\hline UFSC & - & 2 & 3 & 3 & 5 & 6 & 7 & 2 & 2 & 5 & 4 & 39 \\
\hline UFPR & 1 & 1 & 1 & 2 & 3 & 2 & 7 & 8 & 2 & 4 & 6 & 37 \\
\hline UFRJ & 1 & 2 & - & 2 & 1 & 6 & 4 & 6 & 2 & - & 7 & 31 \\
\hline UGF & 1 & 1 & 2 & 2 & 1 & 3 & 6 & 3 & 5 & - & - & 24 \\
\hline USP & - & - & 1 & 1 & 1 & 7 & 1 & 2 & 3 & - & 5 & 21 \\
\hline Unesp & - & - & 1 & - & 2 & 1 & - & 1 & 1 & 4 & 6 & 16 \\
\hline UFMG & 1 & - & - & - & 2 & 1 & - & - & 2 & 2 & 7 & 15 \\
\hline UFPel & - & 1 & 1 & 1 & 1 & 1 & 3 & & 3 & 3 & 1 & 15 \\
\hline UFSM & - & - & 1 & 1 & 2 & 5 & 1 & 1 & 2 & 1 & 1 & 15 \\
\hline UEM & - & 1 & - & 1 & 4 & 1 & - & 2 & 2 & - & 3 & 14 \\
\hline UEL & - & - & 2 & 2 & 3 & 2 & 1 & - & 1 & - & 1 & 12 \\
\hline UFG & 1 & 1 & - & - & - & - & 2 & 2 & 1 & 1 & 3 & 11 \\
\hline UDESC & - & - & - & - & 3 & 1 & 2 & 3 & 1 & & - & 10 \\
\hline UFJF & - & - & 1 & 1 & - & - & - & 2 & 2 & 1 & 3 & 10 \\
\hline
\end{tabular}

Fonte: os autores.

Os dados também salientam uma exogenia nos artigos da revista Movimento, na medida em que $12,1 \%$ do total de publicações desse periódico têm origem na instituição que 0 chancela. Esse dado salienta a maturidade científica desse veículo de comunicação no campo de Educação Física, na medida em que, dentro dos limites econômico-regionais do país, existe uma heterogeneidade institucional no escoamento da publicação nos números dessa revista. ${ }^{26}$

\section{CONSIDERAÇÕES FINAIS}

Os dados apresentados nesta pesquisa permitem inferir com clareza algumas características da revista Movimento e da comunidade científica que nela publica. 
Mesmo com a "crise" no periodismo científico brasileiro, essa revista tem mantido regular a sua periodicidade e pontualidade. Esse fator, aliado à adesão das orientações da Capes para as revistas científicas, permitiu o posicionamento desse periódico no segundo estrato mais alto no Webqualis.

Essa condição, potencializada principalmente após 2007, tem transformado a revista em um local estratégico para o escoamento da produção científica da pós-graduação stricto sensu da subárea sociocultural e pedagógica da Educação Física, apresentando-se, também, como um espaço de circulação de artigos de áreas fronteiriças, como a Educação, as Ciências Sociais e a História.

Os dados indicam que a maior parte dos artigos da revista não indica o financiamento das pesquisas. As questões inerentes à organização das políticas de fomento têm se mostrado pujantes em distintos campos de conhecimento com tendências fortes a limitações de investimentos em virtude da atual conjuntura política e econômica do país. Porém, a situação dos financiamentos encontrada nos artigos veiculados pela revista apresenta-se muito mais como uma questão de compromisso dos pesquisadores com as agências de fomento do que como falta de aporte financeiro público ou privado para o desenvolvimento desses estudos.

A composição autoral na revista Movimento aparece de maneira dispersa, porém com uma forte tendência de crescimento dos trabalhos coletivos. Em virtude dessa característica, no período analisado, o índice de colaboração entre os pesquisadores ainda se apresenta baixo (menos de três por artigo), entretanto a projeção é de que, cada vez mais, o campo científico se movimente de maneira colaborativa.

O crescimento das pesquisas vinculadas a grupos confere força a esse argumento e, mesmo com as preocupações éticas que surgem sobre relações de pesquisa e legitimidade autoral, as possibilidades para a produção do conhecimento articulado em redes de colaboração de proporção nacional são interessantes. Ao mesmo tempo, é importante que os grupos fortaleçam a sua produção, potencializando a pluralidade e o diálogo acadêmico qualificado no campo científico.

No plano da procedência institucional, as publicações da Movimento se organizam de maneira exogênica, fazendo circular artigos originários em instituições de todo o país e também uma quantidade importante de pesquisas de autores estrangeiros. Essa situação indica a maturidade alcançada por esse periódico, apontando a característica democrática sobre 0 conhecimento que a revista veicula em seus fascículos, o que também tem proporcionado ganho de visibilidade internacional da revista Movimento.

Ainda existe no campo científico uma dependência significativa das pesquisas desenvolvidas nos centros econômicos do país, o que, neste estudo, foi compreendida como necessária a um canal de comunicação da ciência que prima pela pesquisa de qualidade. Porém, salienta-se a importância da expansão das políticas econômicas e científicas que permitam a potencialização das pesquisas desenvolvidas na "periferia" do SNPG.

\section{REFERÊNCIAS}

BACHELARD, Gaston. A formação do espírito científico: contribuição para uma psicanálise do conhecimento. Rio de Janeiro: Contraponto, 1996. 
BRASIL. Ministério da Educação. Portaria no 51, de 11 de junho de 2004. Fixa normas e procedimentos para a avaliação anual de propostas de cursos de mestrado e doutorado. Disponível em: <https://www.capes.gov.br/images/stories/download/legislacao/Portaria CAPES 051 2004.pdf>. Acesso em: 15 ago. 2015

CARAMELLI, Bruno. Classificação dos periódicos no sistema QUALIS da CAPES: a mudança dos critérios é urgente! Revista Brasileira de Ortopedia, São Paulo, v. 45, n. 1, p. 1-2, 2010.

CARDOSO, Ricardo L.; MENDONÇA NETO, Octávio R.; RICCIO, Edson L.; SAKATA, Marici C. G. Pesquisa científica em contabilidade entre 1990 e 2003. Revista de Administração de Empresas, São Paulo, v. 45, n. 2, p. 34-45, abr./jun. 2005.

CARNEIRO, Felipe F. B.; FERREIRA NETO, Amarílio; SANTOS, Wagner dos. Práticas científicas em educação física: tradições e tensões. Curitiba: Editora CRV, 2015.

CERTEAU, Michel. A invenção do cotidiano: 1 artes de fazer. Petropolis: Vozes, 1994.

COIMBRA JÚNIOR, Carlos E. A. Desafios da autoria. Cadernos de Saúde Pública, Rio de Janeiro, v. 14, n. 4, p. 1-3, out/dez. 1998.

CORTE, Rachel B. Educação Física Escolar: práticas de pesquisa e saberes científicos em revista (1979-2009). 2009. 170 f. Dissertação (mestrado em Educação Física). Universidade Federal do Espírito Santo, Vitória, 2009.

CURTI, Moreno et al. Impact factor and electronic versions of biomedical scientific journals.

Haematologica, Pavia, v. 80, n. 10, p. 1015-1020, 2001.

DOUTORES 2010: estudos da demografia da base técnico-científica brasileira. Brasília: Centro de Gestão e Estudos Estratégicos, 2010.

EDITORIAL. Movimento, Porto Alegre, v.11, n. 3, set./out. 2005.

EDITORIAL. Movimento, Porto Alegre, v. 12, n. 1, jan./abr. 2006.

EDITORIAL. Movimento, Porto Alegre, v. 13, n. 1, jan./abr. 2007.

GARCIA, Maria L. T. Há pedras no meio do caminho: reflexões sobre a produção científica em periódicos da área de Serviço Social. Argumentum, Vitória, v. 1, n. 1, p. 6-15, jul./dez. 2009.

GARFIELD, Eugene. Citation Indexes for science: a new dimension in documentation through association of ideas. Science, New York, v. 122, n. 3159, p. 108-111, jul. 1955.

GARFIELD, Eugene. Journal impact factor: a brief review. Canadian Medical Association Journal, Canada, v. 161, n. 8, p. 979-980, 1999.

GOLDIM, José R. Aspectos éticos, legais e morais relacionados à autoria na produção científica. Bioética, 2010. Disponível em: <http://www.bioetica.ufrgs.br/autor.htm>. Acesso em: 15 ago. 2015.

JOB, Ivone. Desafios e dilemas da editoração de revistas científicas no Brasil. In: RECHIA, S et al. (Org.). Dilemas e desafios da pós-graduação em educação física. ljuí: Ed. Unijuí, 2015. p. 187203.

JOB, Ivone; FREITAS, K. R. de. A colaboração na produção de artigos dos professores do Programa de Pós-Graduação em Ciência do Movimento Humano da ESEF, da UFRGS, entre 2007 e 2009 : análise de rede social. Movimento, Porto Alegre, v. 16, p. 155-188, 2010. Número especial.

KING, Donald W; TENOPIR, Carol. A publicação de revistas eletrônicas: economia da produção, distribuição e uso. Ciência da Informação, Brasília, v. 27, n. 2, p. 176-182, maio/ago, 1998. 
LARA, Marilda L. G.; LIMA, Vânia M. A. Termos e conceitos sobre redes sociais. In: POBLACIÓN, Dinah A.; MUGNANI, Rogério; RAMOS, L. M. S. V. C. (Org.). Redes sociais e colaborativas em informação científica. São Paulo: Angellara, 2009. p. 141-167.

LAZARONI FILHO, Ari; SILVA, Ana M.; NASCIMENTO, Juarez V.; MASCARENHAS, Fernando. Modus operandi da produção científica em Educação Física: uma análise das revistas e suas implicações. Revista de Educação Física/UEM, Maringá, v. 23, n. 1, p. 1-14, 1. trim. 2012.

LOVISOLO, Hugo R. Comunidades científicas: condições e estratégias de mudança. Educação \& Sociedade, Campinas, v. 18, n. 59, p. 270-297, ago. 1997.

LOVISOLO, Hugo R. A política de pesquisa e a mediocridade possível. Revista Brasileira de Ciências do Esporte, Campinas, v. 24, n. 2, p. 97-114, jan. 2003.

MEHO, Lokman I. The rise and rise of citation analysis. Physics World, Philadelphia, v. 20, n. 1, p. 32-36, 2007.

MEADOWS, Arthur J. A comunicação científica. Brasília: Briquet de Lemos/Livros, 1999.

MOCELIN, Daniel G. Concorrência e alianças entre pesquisadores: reflexões acerca da expansão de grupos de pesquisa dos anos 1990 aos 2000 no Brasil. Revista Brasileira de Pós-Graduação, Brasília, v. 6, n. 11, p. 35-64, dez. 2009.

MONTEIRO, Rosangela et al. Critérios de Autoria em Trabalhos Científicos: um assunto polêmico e delicado. In: Revista Brasileira de Cirurgia Cardiovascular, São José do Rio Preto, v. 9, n. 4, p. 3-8, out./dez., 2004.

MUGNAINI, Rogério; JANNUZZI, Paulo; QUONIAM, Luc. Indicadores bibliométricos da produção científica brasileira: uma análise a partir da base pascal. Ciência da Informação, Brasília, v. 33, n. 2, p. 123-131, maio/ago. 2004.

NASCIMENTO, Ana Cláudia S. Mapeamento temático das teses defendidas nos Programas de Pós-Graduação em Educação Física no Brasil (1994-2008). 2010. Tese (Doutorado em Ciência da Informação) - Programa de Pós-Graduação em Ciência da Informação, Universidade de São Paulo, São Paulo, 2010.

PEREIRA, Potyara A. P. Efeitos das mudanças no sistema Qualis/Capes sobre o serviço social: a experiência do periódico SER social/UnB. Argumentum, Vitória, v. 1, n. 1, p. 16-19, jul./dez. 2009.

SANTOS, Raimundo N. M. dos; KOBASHI, Nair Y. Aspectos metodológicos da produção de indicadores em ciência e tecnologia. In: ENCONTRO NACIONAL DE CIÊNCIA DA INFORMAÇÃO, 2005, Salvador. Anais... Salvador, 2005. Disponível em: < http://www.cinform-anteriores.ufba.br/ vi anais/docs/RaimundoNonatoSantos.pdf>. Acesso em: 15 ago. 2015.

SCHNEIDER, Omar et al. Arqueologia das práticas editoriais: 15 anos de um impresso em Movimento. Movimento, Porto Alegre, v. 15, n. 3, p. 57-85, 2009.

SILVA, Junior V. P. da; GONÇALVES-SILVA, Luiza L.; MOREIRA, Wagner W. Produtivismo na pósgraduação. Nada é tão ruim, que não possa piorar. É chegada a vez dos orientandos! Movimento, Porto Alegre, v. 20, n. 4, p. 1423-1445, out./dez. 2014.

SILVA, Rosana V. de S. O CBCE e a produção do conhecimento em educação física em perspectiva. In: FERREIRA NETO, A. (Org.). Leituras da natureza científica do Colégio Brasileiro de Ciências do Esporte. Campinas, SP: Autores Associados, 2005. p. 45-69. 
SGUISSARDI, Valdemar.; SILVA JÚNIOR, João dos R. Trabalho intensificado nas federais: pósgraduação e produtivismo acadêmico. São Paulo: Xamã, 2009.

SPINAK, Ernesto. Dicionário enciclopédico de bibliometria, cienciometria e informetria. Caracas: Unesco, CII/II, 1996.

STIGGER, Marcos P. et al. Revista Movimento: análise dos sentidos e da repercussão de um periódico que "se faz" no campo da Educação Física brasileira. Movimento, Porto Alegre, v. 16, n. esp., p. 113154, 2010.

VANTI, Nadia A. P. Da bibliometria à webometria: uma exploração conceitual dos mecanismos utilizados para medir o registro da informação e a difusão do conhecimento. Ciência da Informação, Brasília, v. 31, n. 2, p. 152-162, maio/ago. 2002.

VELOSO, Jaques. A Pós-graduação no Brasil: formação e trabalho de mestres e doutores no país. Brasília: Fundação de Aperfeiçoamento de Pessoal de Nível Superior, 2003. v. 2.

YAMAMOTO, Oswaldo H. Editorial, financiamento da pesquisa no Brasil: distorções e desigualdades. Estudos de Psicologia, Natal, v. 5, n. 2, jul./dez. 2000. 